\title{
DEVELOPMENT OF SELECTIVE LASER MELTING PARAMETERS FOR EPITAXIAL CRYSTAL GROWTH
}

\author{
Evgenii BORISOV, Vadim SUFIIAROV, Igor POLOZOV, Dmitriy MASAYLO \\ Peter the Great St. Petersburg Polytechnic University, St. Petersburg, Russian Federation, \\ evgenii.borisov@icloud.com
}

https://doi.org/10.37904/metal.2019.945

\begin{abstract}
Parts from heat-resistant nickel alloys with directional crystallization, as well as single crystals are used in engines and power plants operating under conditions of high temperatures and loads. In this paper, the study of the structure formation in the process of selective laser melting of a heat-resistant nickel alloy was conducted. It is obtained that the length of the forming grains considerably exceeds the thickness of one build layer. The results of the influence of the technological parameters of the selective laser melting process on the directionally crystallized structure characteristics are shown. Elongated grains oriented along the growth direction. The composition, structure, and properties of the obtained samples were studied.
\end{abstract}

Keywords: Selective laser melting, Inconel 718, nickel superalloy, powder metallurgy, additive manufacturing

\section{INTRODUCTION}

Additive technologies are being gradually introduced into industry [1]. Their main advantages allow to complement traditional methods of manufacturing products. In some cases it is even possible to achieve previously impossible results through the use of additive technologies [2]. In particular, this concerns relatively small-scale production, where the timing of bringing the finished product to the market and the ability to quickly change the range of products are important.

Selective laser melting, for example, has been used in areas such as medicine and aerospace, because in these areas there is a need for parts with complex shapes [3]. The processes of structure formation in the process of selective laser melting differ significantly from those in traditional technologies [4]. These differences make it necessary to control processes in a different way. Thus, the purpose of this work was to determine the possible ways for the formation of epitaxial crystal growth during selective laser melting in order to create a directional structure. From a variety of nickel-based alloys, the attention of researchers is attracted to Inconel 718 alloy due to its wide use in gas turbine installations, the manufacture of space products, in the petrochemical and nuclear industries due to its heat and corrosion resistance [5]. The selected Inconel 718 alloy was used in studies devoted to the influence of technological parameters on the characteristics of the structure and properties [6-8]. Investigated options for different scanning strategies, different laser radiation diameters and parameters are published in [9-12]. In this work, unlike others, the heating of the working area was used as an additional parameter to change the cooling conditions of the part and, as a result, the crystallization conditions.

\section{EXPERIMENTAL METHODS}

The samples were manufactured using the selective laser melting machine Aconity3D Midi (Aconity3D GmbH, Germany), shown at Figure 1. The machine is equipped with laser source with variable focal spot diameter, with Gauss power distribution and a maximum power of 1000 watts. Machine is equipped with a module to enable operation with platform preheating up to $1200^{\circ} \mathrm{C}$. 


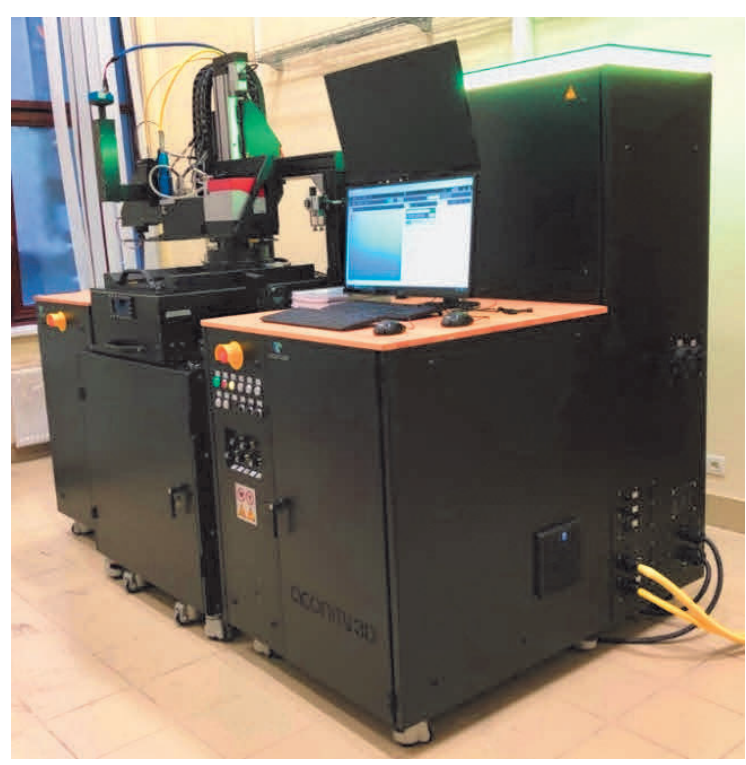

Figure 1 Image of Aconity3D MIDI machine

As an initial material, a powder of the Inconel 718 heat-resistant nickel alloy obtained by gas atomization was used. The particle size distribution was determined using the laser diffraction method on an Analysette 22 NanoTecPlus with a full scale range of $0.01-2000 \mu \mathrm{m}$.

To reveal the size and morphology of the grains, the samples were etched in a reagent with $15 \mathrm{ml} \mathrm{HCl}, 1 \mathrm{ml}$ $\mathrm{HF}$ and $5 \mathrm{ml} \mathrm{HNO}_{3}$. The microstructure was taken on a Leica DMI 5000 light optical microscope in the magnification range from 50 to 1000 times. To study the hardness of specimens a universal hardness tester ZwickRoell ZHU was used.

\section{RESULTS AND DISCUSSION}

The powder of the Inconel 718 alloy used in this study has particle size is in the range: $d_{10}=21.1 \mu \mathrm{m}, d_{50}=$ $37.4 \mu \mathrm{m}, d_{90}=62 \mu \mathrm{m}$. Some of the particles have satellite outgrowths [13]. The presence of such particles is typical for powders obtained with gas atomization. Investigations of the surface morphology of particles at high magnification showed that their surface has some irregularities, reflecting the cast microstructure of the material and refer to cellular-dendritic crystallization.

Selective laser melting is a multi-factor technique. The main influencing parameters are the thickness of the assembly layer, the power of the laser radiation and the distance between the individual laser passes (as determined by the size of the laser spot), as well as the speed of the laser beam along the surface of the powder layer. Changes in these parameters determine the thermal contribution to the material, the permeability of the powder layer, the depth of heating of the material and the fusion of a new layer with the previous layer. With the right choice of synthesis parameters, it is possible to obtain blanks with densities close to $100 \%$, but also these parameters influence the character of crystallization processes occurring in the material. This leads to the formation of a different structure depending on the thermal fields created using this combination of parameters.

SLM process parameters with a similar energy density for the layer thicknesses of 50 and $100 \mu \mathrm{m}$ were used to obtain samples. The parameters were chosen in such a way as to ensure the lowest porosity. For a layer thickness of $50 \mu \mathrm{m}$, laser focusing with a spot size of about $80 \mu \mathrm{m}$ was used, and for a regime with a layer thickness of $100 \mu \mathrm{m}$, focusing with a spot size of about $500 \mu \mathrm{m}$ was used. For the regime with preheating up to $800^{\circ} \mathrm{C}$, the energy density is almost half as much, ensuring the formation of a solid material without pores. This is due to the lower energy that is needed to melt the Inconel 718 alloy at elevated heating temperatures. 
The microstructure of samples made using a layer thickness of 50 and $100 \mu \mathrm{m}$ without preheating of the platform is shown in Figure 2. The microstructure of a sample made with a layer thickness of $50 \mu \mathrm{m}$ has finely dispersed grains without a predominant orientation, whereas the microstructure of a sample made at a layer thickness of $100 \mu \mathrm{m}$ has columnar grains

a)

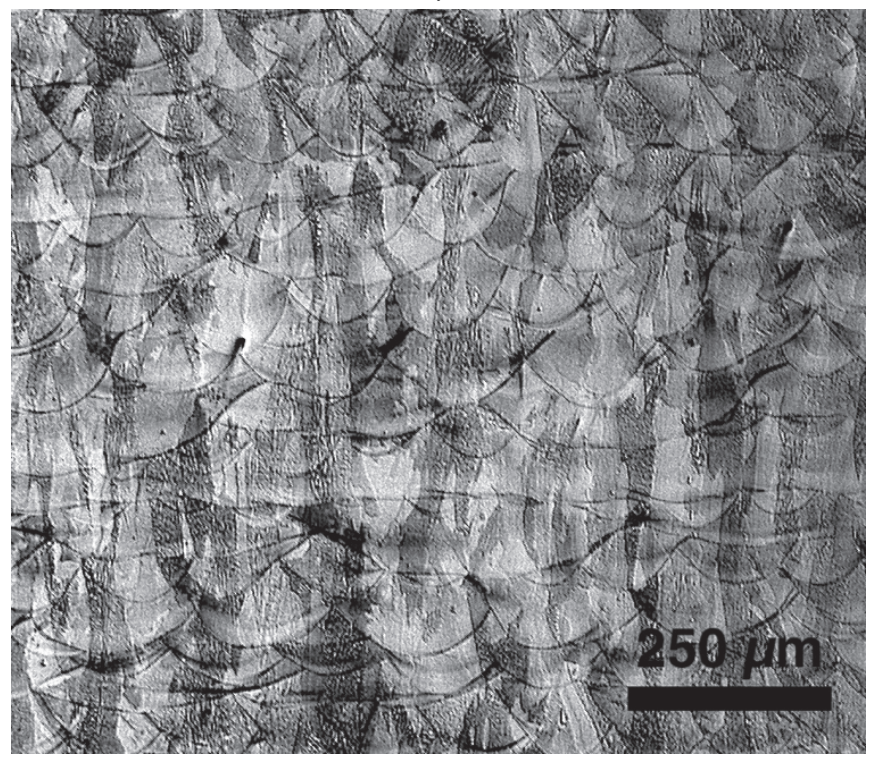

b)

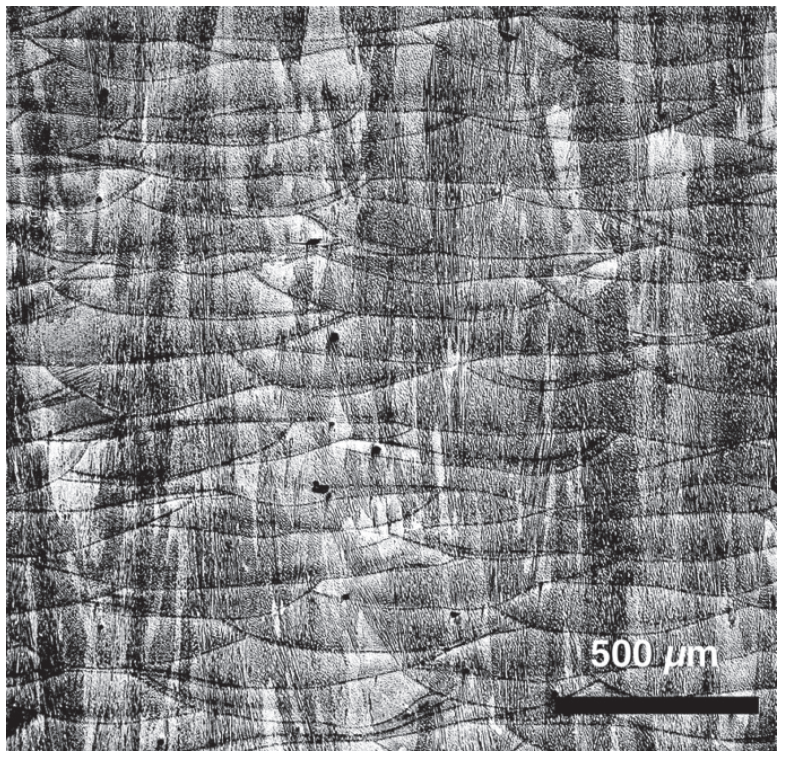

Figure 2 Microstructure of specimens made by SLM with a layer thickness of $50 \mu \mathrm{m}(\mathrm{a})$; and with a layer thickness of $100 \mu \mathrm{m}(\mathrm{b})$ without preheating

The measurements showed that the average cell size at a layer thickness of $50 \mu \mathrm{m}$ is $0.9-1.1 \mu \mathrm{m}$ and at 100 $\mu \mathrm{m}$ is 1.3-2 $\mu \mathrm{m}$ (without preheating) and about 3-6 $\mu \mathrm{m}$ (with preheating) (Figure 3).

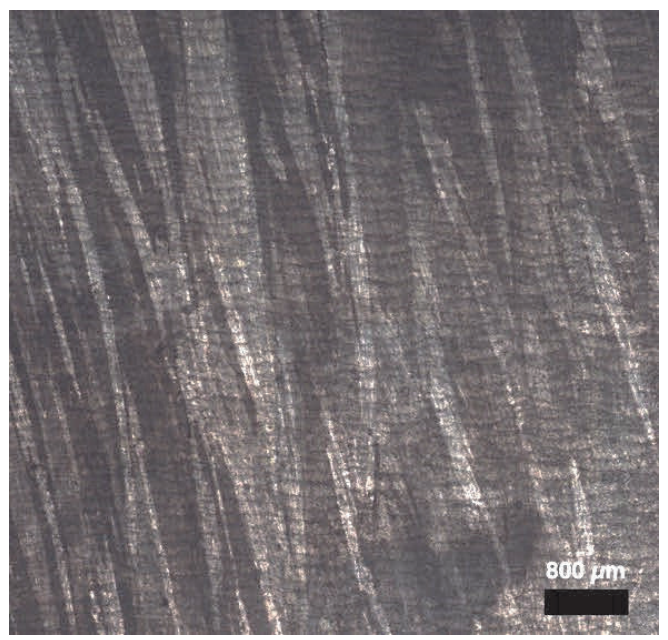

Figure 3 Microstructure of specimen made by SLM with a layer thickness of 100 with $800{ }^{\circ} \mathrm{C}$ preheating

On the microstructure of the sample made using a small layer thickness, it is clearly seen that the bath of the melt has a width comparable in size to the depth. The formation of large elongated columnar grains is most likely caused by differences in the geometry of the bath of the melt, which varies depending on the diameter of the laser spot. For samples of $50 \mu \mathrm{m}$ layer height, the depth of penetration is almost equal to the diameter of the laser, which leads to the fact that the molten bath has a nearly equiaxial geometry (Figure 4, a). 
Since the heat removal during the solidification of the metal occurs predominantly perpendicular to the interface between the liquid and solid phases, for the case of a layer thickness of $50 \mu \mathrm{m}$, the direction of crystal growth differs substantially, which leads to the formation of multidirectional equiaxial grains. When using a regime with a layer thickness of $100 \mu \mathrm{m}$, the ratio of the laser spot diameter to the layer thickness is large, therefore the resulting molten bath has a flatter profile (Figure 4, b), which is clearly seen in the image of the microstructure after etching (Figure 2, b). The heat sink in the molten bath also goes perpendicular to the phase boundary, but in this case it mostly coincides with the axis of growing the part, which causes the formation of grains elongated in the direction of growing due to epitaxial growth.

a)

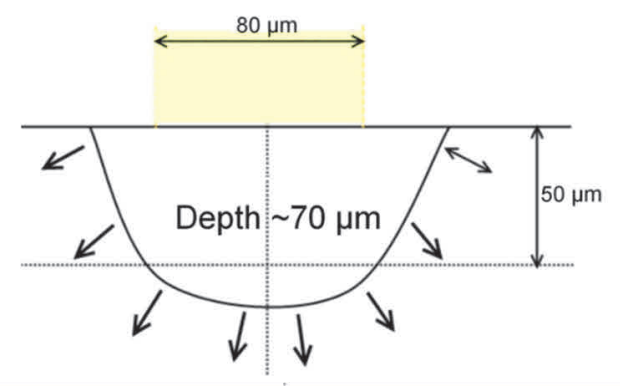

b)

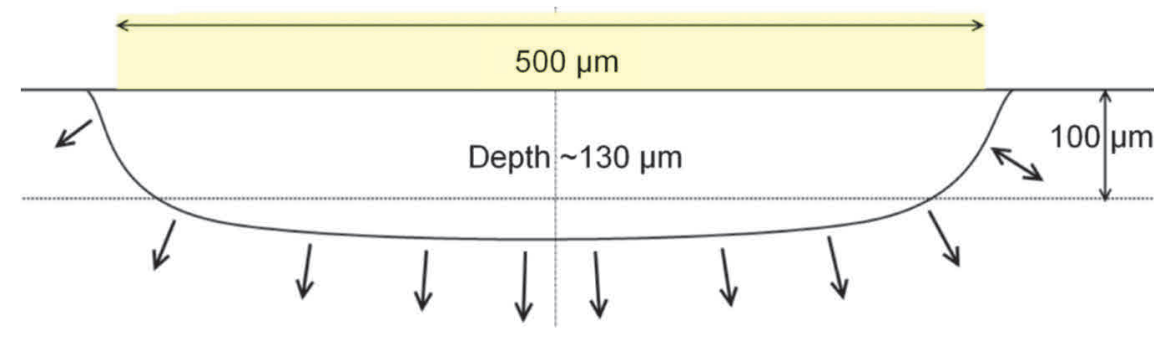

Figure 4 Schematic representation of the geometrical parameters of the molten bath using a) the layer thickness of $50 \mu \mathrm{m}$ and a spot diameter of laser radiation $\sim 80 \mu \mathrm{m}$; b) the layer thickness of $100 \mu \mathrm{m}$ and the laser spot diameter of $\sim 500 \mu \mathrm{m}$

Increasing the heating temperature of the working area leads to a decrease in the intensity of the heat sink. This leads to the fact that the melt bath apparently solidificates more slowly and because of the smaller supercooling the growth of the crystals slows down. In this case, more elongated grains (up to 4-5 mm long) are observed in the formed structure, unlike the case without using preheating (with a grain length of up to 1.5 $\mathrm{mm}$ ), which indicates an increase in the tendency to continue the growth of old grains and a decrease of new grains formation. The formation of new grains violates the epitaxial growth of previously formed grains. If the new grain is well oriented along the direction of growth (in the case of nickel alloys, this is the $<001>$ orientation along the direction of growth), then its growth will continue. Otherwise, it will be forced out by the competitive growth of neighboring grains.

The results of the hardness measurements of the obtained samples are shown in Table 1.

Table 1 Results of HV1 microhardness measurements

\begin{tabular}{|c|c|}
\hline Layer thickness, preheating & Hardness HV1 \\
\hline $50 \mu \mathrm{m}$, without preheating & $335 \pm 10$ \\
\hline $100 \mu \mathrm{m}$, without preheating & $287 \pm 8$ \\
\hline $100 \mu \mathrm{m}$, with preheating & $279 \pm 9$ \\
\hline
\end{tabular}

The dependence of the hardness on the used regimes of sample production is clearly visible. In samples with a small grain size (made using the construction layer thickness of $590 \mu \mathrm{m}$ ), the hardness is greatest. With an 
increase in the layer thickness, and later on with the addition of preheating, the hardness value decreases. This is in good agreement with Hall-Petch law. Thus, it is shown that the addition of heating to $800{ }^{\circ} \mathrm{C}$ influences the mechanical properties of the samples.

\section{CONCLUSION}

The paper presents studies of the conditions of crystallization in the selective laser melting of a nickel alloy. It is shown that the formation of the structure directly depends on the parameters of the molten bath and on the conditions of crystallization. In the case of a layer thickness of $50 \mu \mathrm{m}$ and a small diameter of laser radiation, the orientation of the grains is substantially non-uniform, which leads to a small tendency to epitaxy and, as a result, to a small grain size in the final structure. In both cases, the layer thickness of $100 \mu \mathrm{m}$ tendency to epitaxial growth was manifested to a significant degree, however, the use of preheating allowed to further lengthen the grain by changing the crystallization conditions.

\section{ACKNOWLEDGEMENTS}

This research was supported by Russian Science Foundation grant (project No 19-79-30002).

\section{REFERENCES}

[1] FRAZIER, William E. Metal additive manufacturing: A review. Journal Of Materials Engineering And Performance. 2014. vol. 23, no. 6, pp. 1917-1928.

[2] URIONDO, Adrián, ESPERON-MIGUEZ, Manuel and PERINPANAYAGAM, Suresh. The present and future of additive manufacturing. In the aerospace sector: A review of important aspects. In Proceedings of the Institution of Mechanical Engineers, Part G: Journal of Aerospace Engineering. 2015. vol. 229, no. 11, pp. 2132-2147.

[3] POPOVICH, A. A. et al. Use of additive techniques for preparing individual components of titanium alloy joint endoprostheses. Biomedical Engineering. 2016. vol. 50, no. 3, pp. 202-205.

[4] POPOVICH, A. A. et al. Anisotropy of mechanical properties of products manufactured using Selective Laser Melting of powdered materials. Russian Journal of Non-Ferrous Metals. 2017. vol. 58, no. 4, pp. 389-395.

[5] SUPERALLOYS II: High-Temperature Materials for Aerospace and Industrial Plants. Moscow: Metallurgy, 1995. 385 p. (in Russian).

[6] SUFIIAROV, V.SH., POPOVICH, A.A., BORISOV, E.V. and POLOZOV, I.A. Selective laser melting of heatresistant Ni-based alloy. Non-ferrous Metals. 2015. vol. 1, pp. 32-35.

[7] JIA, Q. and GU, D. 2014. Selective laser melting additive manufacturing of Inconel 718 superalloy parts: Densification, microstructure and properties. Journal of Alloys and Compounds. 2014. vol. 585, pp. 713-721.

[8] TROSCH, T., STRÖßNEr, J., VÖLKL, R. and GLATZEL, U. Microstructure and mechanical properties of selective laser melted Inconel 718 compared to forging and casting. Materials Letters, 2016. vol. 164, pp. 428-431.

[9] JIA, Qingbo and DONGDONG Gu. Selective laser melting additive manufacturing of Inconel 718 superalloy parts: Densification, microstructure and properties. Journal of Alloys and Compounds. 2014. vol. 585, pp. 713-721.

[10] TIAN, Yuan, et al. Rationalization of microstructure heterogeneity in Inconel 718 builds made by the direct laser additive manufacturing process. Metallurgical and Materials Transactions A. 2014. vol. 45, no. 10, pp. 4470-4483.

[11] WANG, Xiaoqing, XIBING, Gong, and CHOU, Kevin. Review on powder-bed laser additive manufacturing of Inconel 718 parts. In Proceedings of the Institution of Mechanical Engineers, Part B: Journal of Engineering Manufacture. 2017. vol. 231, no. 11, pp 1890-1903.

[12] HOLZWEISSIG, M. J., TAUBE, A., BRENNE, F., SCHAPER, M. and NIENDORF, T. Microstructural characterization and mechanical performance of hot work tool steel processed by selective laser melting. Metallurgical and Materials Transactions B. 2015. vol. 46, no. 2, pp. 545-549.

[13] SUFIIAROV, V. Sh. et al. Layer thickness influence on the Inconel 718 alloy microstructure and properties under selective laser melting. Tsvetnye Metally. 2016. vol. 1, pp. 81-86. 